\title{
Digital access to culture: copyright in photographs of two-dimensional art under Australian copyright law
}

\begin{abstract}
Jani McCutcheon
Associate Professor, University of Western Australia

Photographs of cultural collections are an essential means of disseminating art and democratizing access to culture. This article reviews the policies of five major Australian galleries on access to their collections. It finds they tend to claim copyright in photographs of their collections, including of public domain works. This reflects a perceived entitlement to control access to their digital collections, often bolstered by a misstatement of copyright exceptions, restrictive quasi-copyright contract terms, licensing practices, and physical property rights in photography's appurtenances. This curbs the emancipatory potential of digitization, generating a conflict between the property interests of cultural institutions and the public interest in enhanced access to culture. The problem is particularly acute with respect to images of public domain art, exclusive control over which diminishes the public domain. This article considers the novel question of whether copyright subsists in photographs of two-dimensional art under Australian law, arguing that such photographs lack the originality indispensable to copyright subsistence. This conclusion significantly undermines cultural institutions' licensing models and challenges misconceptions of property rights in the photographic surrogates of two-dimensional cultural objects. The article urges cultural institutions to liberate the digital surrogates of public domain art to enhance access to cultural capital.
\end{abstract}

Keywords: copyright, originality, photographs, digitization, culture, access, contract, property

\section{INTRODUCTION}

In principle a work of art has always been reproducible ... Just as water, gas, and electricity are brought into our houses from far off to satisfy our needs in response to a minimal effort, so we shall be supplied with visual or auditory images, which will appear and disappear at a simple movement of the hand, hardly more than a sign. ${ }^{1}$

Walter Benjamin's comments, made in 1936, are almost uncannily prescient in this modern age of the ubiquitous image. They could well describe the Internet's seemingly inescapable invasive probing and its cacophony of images. The incredible potential of the Internet as a disseminative instrument has been embraced by a number of cultural institutions as a means of digitally sharing their artistic collections. Recently, The New York Metropolitan Museum of Art made nearly 400000 high-resolution images of

1. W Benjamin, 'The Work of Art in the Age of Mechanical Reproduction', in H Arendt (ed), Illuminations: Walter Benjamin 1892-1940 (Jonathan Cape, London 1970) 220. 
its public domain works accessible ${ }^{2}$ under a creative commons zero licence, ${ }^{3}$ emulating other institutions and organizations like Pharos ${ }^{4}$ and Amsterdam's Rijksmuseum. ${ }^{5}$ How many Australian galleries do the same? This article reviews the websites of Australia's five major public art galleries to determine their policies and practices on providing access to digital representations of their collections. The evaluation revealed that no gallery provides unconditional open access to high-resolution images of public domain works. The article summarizes the major features of each gallery's digital access policies and critically analyses them in the context of copyright law. The survey reveals that a number of websites include statements which intimate a universal claim of copyright in all website content, including photographs of public domain two-dimensional cultural objects. ${ }^{6}$ The article critiques these claims, exploring the under-investigated topic of originality in photographs under Australian copyright law. It explains why photographs of two-dimensional artworks will almost invariably lack the originality essential to copyright subsistence. Particularly problematic are claims to copyright in photographs of public domain works, which have the malign consequence of effectively removing those works from the public domain and transferring them to the private ownership of cultural institutions through the photographic surrogate. The article also explains how galleries' express or tacit assertions of copyright in digital photographs are bolstered by galleries' contractual terms and the possessory force of their real and chattel property rights, which moderate access to photographic files and cultural objects. Through contract, galleries impose restrictions on the use of digital and physical cultural materials, and control their availability across a spectrum of dissemination and licensing models. This reinforces galleries' express or tacit copyright claims in digital photographs. The article explains how this melange of copyright, contract and property rights unduly hampers access to cultural objects, and fosters the illusion of property rights in them.

This raises important issues about access to cultural heritage. Millions of artworks are housed by our cultural institutions, most of which are publicly funded. Physical access to these works is constrained by a number of factors. Viewing works in situ is only possible for those who are able to physically visit the gallery. Touring exhibitions to remote and regional locations is prohibitively expensive and risky. Galleries have limited exhibition space, and can only display a tiny proportion of their collections at any one time. ${ }^{7}$ Some works are too fragile to be frequently exposed to light or handled.

2. Anon, 'The Met Makes Its Images of Public-Domain Artworks Freely Available through New Open Access Policy' February 7, 2017 <http://www.metmuseum.org/press/news/2017/ open-access $>$.

3. <https://creativecommons.org/publicdomain/zero/1.0/>.

4. <http://pharosartresearch.org/>.

5. <https://www.rijksmuseum.nl/en/rijksstudio?ii=0\&p=0\&from=2017-02-21T02\%3A54\% 3A03.9685255Z>.

6. The particular terms of these websites are discussed below in Part 1. Similar claims are made by overseas institutions. See, for example, the Museum of Fine Arts Boston, which stipulates on its website 'Text and images on the MFA's Web site - created as a public educational resource - are the property of the MFA and are protected by copyright' <http://www.mfa.org/ collections/mfa-images/web-use-and-gallery-photography>.

7. See, for example, the National Gallery of Victoria: 'as the NGV has approximately 70,000 artworks in its collection, only a small percentage can be on display at any one time', National Gallery of Victoria, Submission No. 142 to Australian Law Reform Commission, Copyright and the Digital Economy 2012. 
Most, if not all, of these access problems can be ameliorated by providing online access to images of the Gallery's collection. While a digital viewing experience may never surpass exposure to the 'aura' ${ }^{\prime}$ of the original artwork, it is frequently the only alternative. This is reinforced by the reality that, in many cases, only the cultural institution can photograph the objects in their collections. Some cultural institutions prohibit the taking of photographs of their collections, and sometimes they robustly enforce those policies. ${ }^{9}$ Others permit the taking of photographs for personal use only, and contractually prohibit downstream reproductions. ${ }^{10}$

In its 2013 report on Copyright and the Digital Economy, the Australian Law Reform Commission recognized that one of the main issues facing cultural institutions in fulfilling their public service missions was the provision of access by the public to their materials. ${ }^{11}$ In its report, Creative Australia, the Australian government emphasized that 'digitisation of collections and increasing online engagement ... will exponentially increase the value and role of our national collections in telling Australian stories'. ${ }^{12}$

Many institutions recognize that enhanced digital access is consonant with their mandate to provide access to their collections and undertake education programmes, ${ }^{13}$ and has many benefits. ${ }^{14}$ To foster these objectives, during the Australian Law Reform Commission's enquiry, a number of cultural institutions advocated for copyright reform which would give them greater freedom to engage in mass digitization projects and routine digitization of collection material. ${ }^{15}$

8. '[T]hat which withers in the age of mechanical reproduction is the aura of the work of art': Walter Benjamin, 'The Work of Art in the Age of Mechanical Reproduction' in Hannah Arendt (ed), Illuminations: Walter Benjamin 1892-1940 (Jonathan Cape, London 1970) 223.

9. Recently a French art student was forcibly removed from the Louvre for contravening its no photography policy. See Claire Hache, 'Louvre: Un Etudiant Affirme Avoir Eté "Escorté" Par Des CRS Pour Avoir Pris Des Photos' L'Express, 08/03/2017 <http://www.lexpress.fr/culture/louvreun-etudiant-affirme-avoir-ete-escorte-par-des-crs-pour-avoir-pris-des-photos_1887187.html>.

10. Australian examples are discussed below.

11. Australian Law Reform Commission, Copyright and the Digital Economy Report No. 122 (2014) para 11.8.

12. Commonwealth of Australia, Creative Australia: National Cultural Policy 100.

13. 'The challenges for public cultural institutions such as the AGNSW centre around our mandate to provide access to our collection and exhibitions, maintaining and preserving our collection and providing educational programs in a climate of changing technologies, diverse audiences, diminishing budgets and shorter timeframes': Art Gallery of New South Wales, Submission No. 111 to Australian Law Reform Commission, Copyright and the Digital Economy 2012; 'The NGV feels making images of works available on Collection Online gives great exposure and visibility to artists; it also serves to adhere to our mandate of access. Often individual artists, not represented by a collection agency, are very pleased for their works to appear online at no charge. These artists have cited the benefits of including their works online, as part of the prestigious state collection': National Gallery of Victoria, Submission No. 142 to Australian Law Reform Commission, Copyright and the Digital Economy 2012.

14. See Museums Victoria, Submission No. 522 to Australian Law Reform Commission, Copyright and the Digital Economy 2012: 'The benefits of putting material online are: 1. Public purpose (benefit/good) 2. Provide access to these works for the purposes of research, education, personal research (e.g. genealogical research) 3. Create online educational material to support the school curriculum 4. Foster/enable learning by encouraging community involvement and receiving useful information back to the cultural agency about items in the State collections when people find this material their most common response is to want to share the information with the source'.

15. Australian Law Reform Commission, Copyright and the Digital Economy Report No. 122 (2014) para 11.10. For example, the National Gallery of Victoria submitted that '[a]ny 
The imperative to enhance digital access to cultural collections is an important background consideration in the following discussion of galleries' policies.

\section{PART 1: A SUMMARY OF THE POLICIES OF AUSTRALIA'S FIVE MAJOR GALLERIES ON DIGITAL ACCESS TO THEIR COLLECTIONS}

\section{AGWA}

The Art Gallery of Western Australia (AGWA) offers a 'small selection of the Gallery's Collection ... online', which 'is a representative sample'. ${ }^{16}$ AGWA then states under the heading 'Copyright and the reproduction of works':

If you wish to reproduce any works in the State Art Collection, housed by the Art Gallery of Western Australia, please contact our Registration Department. We can supply you with the conditions and costs associated with your request and grant appropriate reproduction rights.

... please complete an Application to Reproduce Works of Art form ... ${ }^{17}$

Charging a 'service fee', the AGWA states: 'Fees are payable for the reproduction of items from the collection of the Art Gallery of Western Australia. These fees are in addition to charges for the supply of photographic material and are not copyright fees'. ${ }^{18}$

AGWA's website includes the statement that:

Images may not be copied or stored by any means, electronic or otherwise, except for the purpose they were originally supplied ... The supply of digital image files from the Gallery does not confer the rights to store or reproduce them or make them available to the public in any medium or form except for the reproduction or communication rights stipulated on the Licence to Reproduce. Nor does the supply of photographic material imply the availability of these rights ...

Acknowledgment of the Art Gallery of Western Australia as owner must be included with all reproduction and the following credit line used: State Art Collection, Art Gallery of Western Australia. ${ }^{19}$

In its 'application to reproduce artworks' form, the AGWA states that it 'provides a quality photographic service for items held in its Collection. No non-Gallery professional photography is permitted; this is in order to maintain a consistent standard

amendments would need to specifically address the concerns of cultural institutions to promote free and fair use of cultural collections', National Gallery of Victoria, Submission No. 142 to Australian Law Reform Commission, Copyright and the Digital Economy 2012. Museums Victoria argued that '[i]f we are required by our enabling Acts to make our collections available and accessible, and the chief way to do that is electronically, then mass digitisation needs to be facilitated', Museums Victoria, Submission No. 522 to Australian Law Reform Commission, Copyright and the Digital Economy 2012. Museums Victoria argued for a 'specific illustrative purpose to enable the GLAM sector to share copyright works in their collection online': Museums Victoria, Submission No. 522 to Australian Law Reform Commission, Copyright and the Digital Economy 2012.

16. <http://www.artgallery.wa.gov.au/collections/copyright.asp>.

17. Ibid.

18. <http://www.artgallery.wa.gov.au/collections/documents/2016-ApplicationtoReproduce WorksofArt_000.pdf>.

19. Ibid, emphasis added. 
and for copyright purposes'. ${ }^{20}$ The Gallery also states that it 'only allows reproductions from its own photographic material to ensure highest quality control'. ${ }^{21}$

All of these statements combine to imply that permission must be obtained from AGWA to reproduce 'any works in the State Art Collection', and that AGWA has the exclusive authority to demand compliance with its licensing terms and 'grant appropriate reproduction rights'. There is a blanket prohibition on the copying or storing of images, except for the purposes for which they were originally supplied. The suggested source of AGWA's authority is, or clearly includes, copyright law. This stems from the chosen heading 'Copyright and the reproduction of works', the references to 'reproduction rights', and AGWA's statement that it restricts the taking of photographs of its collection 'for copyright purposes'. Combined, these statements suggest that AGWA claims copyright in its photographs of the cultural objects, and that this copyright is seen as a means of control. The stipulation that AGWA must be acknowledged as 'owner' is more ambiguous, since ownership could refer to the digital files supplied to the licensee, or to the physical chattels depicted in the licensed photographic images. However, in combination with the other implications, the claim of ownership strengthens the tacit assertion of copyright.

\section{Art Gallery of NSW}

The Art Gallery of New South Wales makes the following statements on its website 'Copyright Policy':

The text, images and all data ('the content') of the Art Gallery of NSW website are copyright. Copyright in the content of the website remains with the Gallery and other copyright owners as specified. ... The content of this website (or any part of it) may not be:

- posted to any other website;

- modified, republished, distributed, reproduced or communicated in any form

- used for any public performance or display including a transmission over a network

- reproduced in any form including without limitation, the extraction and/or storage in any retrieval system or inclusion in any other computer program or work (except as is incidental to viewing the Gallery website).

Contravention is an infringement of the Australian Copyright Act 1968.

All images are protected by digital watermarks. ${ }^{22}$

This statement constitutes a universal claim to copyright in all of the content on the website, including the digitized cultural objects. This is reinforced by the declaration that contravention of the Gallery's terms is an infringement of the Copyright Act. The Gallery also states:

The content of this website may be used:

- for private research and study;

- for research and study as defined by section 40 of the Copyright Act 1968.

All other uses of the content of this site require Gallery permission and permission of the copyright owner (where applicable). Applications for authorised use must be made to the Image Reproduction Department at imageReproduction@ag.nsw.gov.au ${ }^{23}$

20. Ibid.

21. Ibid.

22. <https://www.artgallery.nsw.gov.au/about-us/about-website/copyright-policy/>.

23. Ibid. 
The Gallery makes similar statements in relation specifically to 'images of artworks on this website'. ${ }^{24}$

The fact that this is worded essentially as a fair dealing copyright exception, and express reference is made to section 40 of the Copyright Act 1968 (Cth) (hereafter 'the Act' $)^{25}$ implies that, outside of those purposes, use would be an infringement of copyright. Again, this is a tacit claim to copyright in all of the content, including photographs of public domain material.

The difficulty with many of these statements is that they do not distinguish between copyright and non-copyright material. Reproductions of a photograph of a copyright work may, indeed, constitute infringement of the copyright in the photographed work ${ }^{26}$ unless a copyright exception applied. However, that is not the case with respect to photographs of public domain paintings or photographs, because copyright has expired in the painting or photograph, and (as discussed below) there is almost certainly no originality in the photograph of it. Therefore, to make a blanket statement that only fair dealings are permitted with respect to any of the institution's works is an overstatement, because it is perfectly permissible to deal with photographs of public domain paintings or photographs. Assertions that permission is universally required, subject to fair dealing exceptions, clothes all of the works on the website with copyright because most viewers would not know that permission is only legally required for copyright extant works, nor would they necessarily know which is a copyright work and which is not.

The Gallery also warns that ' $[y]$ ou may not use the content for any purpose other than as specified above without the express written consent of the Gallery and relevant copyright holders'. ${ }^{27}$ In relation specifically to 'images of artworks on this website', the Gallery specifies that these 'may be used for research, study and other related exceptions as defined by section 40 of the Copyright Act 1968 (as amended) without applying for specific permission', but that 'all other uses of the content of this site require Gallery permission and permission of the copyright owner (where applicable)' ${ }^{28}$ It is understandable to remind readers of the necessity to request the consent of 'relevant copyright holders' ${ }^{29}$ for copyright extant works; however, it is erroneous to suggest that the consent of the Gallery is required, unless the Gallery has a copyright interest in the content or is an agent of the copyright owner. The Gallery also understates the scope of the copyright exceptions, limiting permissible use to the research or study defence, when all fair dealings, including parody or satire, criticism or review, and reporting of news, may also exempt the user from liability.

24. 'Images of artworks on this website may be used for research, study and other related exceptions as defined by section 40 of the Copyright Act 1968 (as amended) without applying for specific permission', <https://www.artgallery.nsw.gov.au/research/artwork/using-images-ofthe-collection/>.

25. Section 40(1) of the Act provides that 'A fair dealing with a literary, dramatic, musical or artistic work, or with an adaptation of a literary, dramatic or musical work, for the purpose of research or study does not constitute an infringement of the copyright in the work'.

26. But not necessarily, for the reasons explained below, the photograph.

27. <https://www.artgallery.nsw.gov.au/about-us/about-website/copyright-policy/>, emphasis added.

28. <https://www.artgallery.nsw.gov.au/research/artwork/using-images-of-the-collection/>.

29. The Gallery indicates that ' $[\mathrm{w}] \mathrm{e}$ can supply details of copyright holders where possible. It is the sole responsibility of the client to gain copyright permission to reproduce the image from the copyright holder of the works requested', <https://www.artgallery.nsw.gov.au/research/artwork/usingimages-of-the-collection/>. 


\section{National Gallery of Victoria}

The National Gallery of Victoria's website states that 'copyright in all materials and/or works comprising or contained within this website remains with the National Gallery of Victoria and other copyright owners as specified' ${ }^{30}$ Again, this statement is at minimum ambiguous, at the most, an overstatement. It is an overstatement because it suggests that copyright subsists in all materials on the website, when clearly this is not the case, for the reasons explained above. It is ambiguous because it could be read to mean that where copyright exists, it is owned either by the Gallery or 'other copyright owners as specified'.

The Gallery also states categorically that '[n]o image or documentation displayed on this site may be reproduced, communicated or copied ... without the Gallery's permission' ${ }^{31}$ and that ' $[\mathrm{u}]$ nauthorised commercial publication or reproduction of any part of the NGV Collection is prohibited'. ${ }^{32}$ Under the heading 'Copyright and the Reproduction of Works', the NGV states that '[i]f you wish to reproduce any works featured in this website, you should first contact the Copyright Co-ordinator, who can supply you with the conditions and costs associated with your request and grant appropriate reproduction rights' ${ }^{33}$

Again, while the source of the Gallery's authority to control such conduct is not overtly explained, that it is grounded in copyright is strongly implied by the nature of the rights that are purportedly constrained - communication, reproduction and copying ${ }^{34}$ - by the heading chosen ('Copyright and the Reproduction of Works') and by the Gallery's final statement that '[c]ontravention is an infringement of the Australian Copyright Act 1968'.35

The National Gallery's statements in relation to permitted use better reflect existing copyright exceptions, but also contain important gaps:

You may copy, distribute, display, download, communicate or otherwise freely deal with the information, data, documents, pages and images on this website for your own personal use for the purposes of study or research, or by Australian teachers for non-commercial educational purposes in Australian schools, universities and TAFE institutions only, provided that you do not repurpose or alter the published material in any way.

However, you must obtain specific permission from the National Gallery of Victoria if you wish to:

(a) charge others for access to the material (other than your own costs),

(b) include the material in advertising or a product for sale, or

(c) modify, repurpose or alter the published material.

30. <https://www.ngv.vic.gov.au/about/reports-and-documents/copyright-and-reproductions/>.

31. Ibid.

32. <https://www.ngv.vic.gov.au/about/reports-and-documents/19357-2/>.

33. <https://www.ngv.vic.gov.au/about/reports-and-documents/copyright-and-reproductions/>.

34. Which exactly replicate the exclusive rights in ss 31(1)(iv), 85(1)(c) and 86(c) ('communicate the work to the public'); s 31(1)(i) ('reproduce'), and 85(1)(a) and 86(a) ('copy') of the Act.

35. <https://www.ngv.vic.gov.au/about/reports-and-documents/copyright-and-reproductions/>. This is further reinforced by an additional statement on the same page: 'If you wish to reproduce any works featured in this website, you should first contact the Copyright Co-ordinator, who can supply you with the conditions and costs associated with your request and grant appropriate reproduction rights', emphasis added. A similar statement appears on another page: 'If you wish to reproduce any works displayed at the NGV or which appear on the NGV website, you should first contact the Permissions and Copyright Co-ordinator, who may be able to supply you with the conditions and costs that may be associated with your request', <https://www.ngv. vic.gov.au/about/reports-and-documents/19357-2/>. 
No image or documentation displayed on this site may be reproduced, communicated or copied (other than for the purposes listed above; criticism or review, or reporting the news) without the Gallery's permission. Use and referral is allowed for the purposes of research or study so long as full and proper attribution is given. For Indigenous works, this may include the artist and community. Unauthorised commercial publication or reproduction of any part of this website is specifically prohibited. Contravention is an infringement of the Australian Copyright Act $1968 .{ }^{36}$

This articulates the essential features of most of the Act's fair dealing defences, ${ }^{37}$ and the educational statutory licence, ${ }^{38}$ but again excludes the parody or satire defence. It also burdens users with limitations which are not found in the exceptions. For example, a commercial purpose will not necessarily obviate the fairness of a dealing, ${ }^{39}$ nor will 'personal use' necessarily guarantee it. There is also no requirement of attribution imposed by the research or study defence; this is a requirement of the criticism or review defence. ${ }^{40}$ Further, if a fair dealing exception applies, there is no prohibition on repurposing or altering published material (and indeed the parody or satire defence will often only apply when such repurposing or alteration has occurred, due to the nature of parody and satire). Other rights, such as moral rights, may prevent such material alteration, ${ }^{41}$ but not the copyright exceptions.

\section{Art Gallery of South Australia}

The terms of access to the Art Gallery of South Australia's online collection are as follows:

Access to and use of the images of the works of art within the Art Gallery of South Australia Online Gallery are subject to the following terms and conditions:

1. The images of works are made available for the strictly limited use of viewing the works online.

2. Copying, redistribution or communication of any image on this Site for commercial use or personal gain is strictly prohibited.

36. <http://www.ngv.vic.gov.au/about/reports-and-documents/copyright-and-reproductions/>.

37. Other pages on the NGV website only refer to the research or study defence: 'No image, documentation or sound recording displayed at the NGV or appearing on the NGV website may be reproduced, communicated or copied without permission, other than for the purposes of research or study', <https://www.ngv.vic.gov.au/about/reports-and-documents/19357-2/>.

38. See generally Part VB of the Act.

39. '[R] esearch is not limited to non-commercial or private contexts', $\mathrm{CCH}$ Canadian Ltd $v$ Law Society of Upper Canada [2004] 1 SCR 339. See also Television New Zealand v Newsmonitor Services Ltd (1993) 27 IPR 441, [463] (Blanchard J): 'a fair dealing for purposes of research ... can be something done with a commercial end in view'.

40. Section 41 of the Act provides: 'A fair dealing with a literary, dramatic, musical or artistic work, or with an adaptation of a literary, dramatic or musical work, does not constitute an infringement of the copyright in the work if it is for the purpose of criticism or review, whether of that work or of another work, and a sufficient acknowledgement of the work is made'. An identical provision is contained in s 103A.

41. See the right of integrity and related provisions in ss 195AI, 195AJ, 195AK, 195AL, 195ALA and 195ALB of the Act. 
3. Except as is necessary to view the Online Gallery, or as is permitted pursuant to the Copyright Notice linked to this Site, images may NOT be:

- Extracted, downloaded or stored on any retrieval system or included in any other computer program or work.

- Copied, modified, distributed, reproduced, communicated or dealt with in any way without the permission from the copyright holder and the Gallery.

4. Requests to use any image of a work on this site must be made to the Art Gallery of South Australia's Image Sales Office email or telephone +6180882077020 or fax +61808 $82077070 .{ }^{42}$

These terms are the most draconian of the cultural institutions surveyed. They ostensibly limit permissible use to viewing the works online, and expressly prohibit copying, redistribution or communication of the images for any purpose without the copyright holder and the Gallery's permission. The only suggestion of a relaxation of these terms is the permissible use 'pursuant to the Copyright Notice linked to this Site'. At the bottom of the page is a very small 'copyright' link, which links to the following 'Copyright Statement':

1. Copyright in this Site is owned by the Government of South Australia.

2. Copyright in the material included on this Site is either owned by or licensed to the Government of South Australia. Copyright in the material provided by the Government of South Australia agencies and instrumentalities and non-government organisations belongs to those agencies and organisations.

3. Apart from any use permitted by the Copyright Act 1968, the Government of South Australia grants visitors to the site a licence to download, display, print and reproduce this material for private use or for non-commercial purposes only.

4. No licence to publish, communicate, modify, commercialise or alter this material is granted. For reproduction or use of the Government of South Australia's copyright material beyond this limited licence, permission must be sought from the relevant agency or instrumentality of the Government of South Australia, as identified in the relevant WWW page. ${ }^{43}$

This has the language of a universal government website copyright notice. Indeed, an identical notice can be found at the South Australian Department of Treasury and Finance website. ${ }^{44}$ The end result is that the Gallery of South Australia's terms and conditions relating to access to online cultural material are ambiguous. The terms would appear to be subject to the Copyright Statement, which conflicts with the terms. Whereas the terms restrict permissible use to online viewing only, the Copyright Statement permits use exempted by the Copyright Act, and confers a licence 'to download, display, print and reproduce this material for private use or for non-commercial purposes only'. Thus the Copyright Statement essentially nullifies the prohibitions contained in the online collection terms, and it is very difficult to reconcile the contesting terms. In any event, both the online collections terms and the Copyright Statement are problematic. The online collection terms clearly offend the fair dealing provisions of the Copyright Act, which exempt a number of the prohibited uses from liability. This raises the contentious issue of the extent to which contractual terms can exclude exemptions conferred under the Act. ${ }^{45}$ And again, both documents purport to

42. <https://www.artgallery.sa.gov.au/agsa/home/Collection/>.

43. <https://www.artgallery.sa.gov.au/agsa/home/About/docs/copyright.html>.

44. <https://www.treasury.sa.gov.au/copyright>.

45. See generally, Copyright Law Review Committee, Copyright and Contract (2002). 
unconditionally restrict commercial use, when the nature of the use is only one factor considered in the fairness analysis under the fair dealing provisions and a commercial purpose will not necessarily vitiate fairness. ${ }^{46}$

Whether the Gallery of South Australia claims copyright in the digital photographs of its collections is ultimately unclear. The online collection terms make no express reference to copyright as the basis of the Gallery's authority to dictate terms of access. It appears that the Gallery is relying on contract to achieve its control. However, the apparent incorporation of the terms of the Copyright Statement into the online collection terms ultimately entrenches the ambiguity. The Copyright Statement does include claims of copyright, but they include the anomalous claims that the copyright in the material on the gallery's website is either owned by the Government of South Australia, its agencies, instrumentalities or by non-government organizations. Clearly, that is not the case, since much of the copyright in the cultural objects displayed on the website would be owned by the authors of those works or assignees of the copyright in them.

\section{Queensland Art Gallery/Queensland Gallery of Modern Art (QAGOMA)}

On its 'image reproductions' page, QAGOMA states:

Digital images of artworks in the Gallery's Collection can be licensed for a range of uses, including print and online publications, film and multimedia, selected commercial products, and research....

Images of artworks on Collection Search may be used only for private research and study and other exceptions as defined by section 40 of the Copyright Act 1968 without asking for specific permission.

All other uses require Gallery permission and permission of the copyright holder. ${ }^{47}$

On entering the search facility of the Queensland Art Gallery's online collection, the following Copyright Statement is encountered:

The Queensland Art Gallery respects the rights of all artists and copyright holders. No image may be reproduced, transmitted or copied without permission. Contravention is an infringement of Australia's Copyright Act 1968. Requests for reproduction and publication of the Gallery's art works should be referred to Reproductions. ${ }^{48}$

The Gallery purports to contractually incorporate the terms of this statement through a browse-wrap facility which is next to the 'search' button in the following terms: 'By using the QAG I GoMA Collection Online Search you agree to accept the conditions of use as per the Copyright Statement below'.

Again, the universal stipulation in the Copyright Statement that "no image may be reproduced, transmitted or copied without permission' comprehensively ignores the fair dealing exceptions, which permit just that conduct. It also conflicts with the statement on the image reproductions page, which does acknowledge the fair dealing exceptions. Again, as with other galleries mentioned above, QAGOMA's Copyright Statement fails to acknowledge that some, if not many, of the Gallery's works are

46. ' $[\mathrm{R}]$ esearch is not limited to non-commercial or private contexts', CCH Canadian Ltd v Law Society of Upper Canada [2004] 1 SCR 339. See also Television New Zealand v Newsmonitor Services Ltd (1993) 27 IPR 441 [463] (Blanchard J): 'a fair dealing for purposes of research ... can be something done with a commercial end in view'.

47. <https://www.qagoma.qld.gov.au/copyright-image-reproductions >.

48. <http://collection.qagoma.qld.gov.au/qag/imu.php?request=search>. 
in the public domain, and can be freely dealt with. The suggestion is that all material is subject to copyright, augmented by that familiar statement that '[c]ontravention is an infringement of Australia's Copyright Act 1968'.

The combined effect of the galleries' policies is a chilling of access to digital reproductions of artworks and a propertization of the public domain. In most cases, the policies are ambiguous and confusing, and do not always accurately represent copyright law. They do, however, convey a consistent message that the gallery has the exclusive legal authority to grant and condition access to digital reproductions of cultural objects, and at least one source of that authority is copyright law. Users would be forgiven, then, for hesitating before using any of the material which is accessible through the Gallery websites. The legal risk in doing so was pointedly and somewhat irreverently illuminated in 'Display At Your Own Risk', a 2016 research project by Andrea Wallace and Ronan Deazley. This event was a 'research-led exhibition experiment featuring digital surrogates of public domain works of art produced by cultural heritage institutions of international repute'. ${ }^{49}$

\section{PART 2: ORIGINALITY IN PHOTOGRAPHS UNDER AUSTRALIAN COPY- RIGHT LAW}

As mentioned, many of the galleries tacitly or explicitly assert a universal copyright claim to all material digitally represented on their websites. This article now questions the legal basis for those claims to the extent that they extend to photographs of public domain paintings and photographs. It is important to ascertain this, because the suggestion of copyright subsistence underscores and strengthens the galleries' proprietary claims to the artworks, and correspondingly may chill access to public domain material.

Perhaps surprisingly, there is no Australian authority that directly concerns the copyright status of photographs. Thus we must revert to essential principles. Copyright subsists in authored works, including artistic works, which are original. ${ }^{50}$ Photographs are artistic works. ${ }^{51}$ Authorship and originality are correlative, ${ }^{52}$ and thus the author of a work supplies the requisite originality. In IceTV, French CJ, Crennan and Kiefel JJ ('the French judgment') observed, obiter, that originality 'means that the creation (ie the production) of the work required some independent intellectual effort', ${ }^{53}$ adopting the formulation of Isaacs J in Sands \& McDougall Pty Ltd v Robinson (1917) 23 CLR 49 at 52, in which he expressly connected the independent intellectual effort of authors to the "exercise of judgment and discrimination'. In IceTV, the French judgment warned that '[n]ot every piece of printing or writing which conveys information will be subject to copyright' ${ }^{54}$ and Gummow, Hayne and Heydon JJ observed that it will be a question of 'fact and degree' to determine whether one or more authors 'have expended sufficient effort of a literary nature to be considered an author of that work within the meaning of

49. <http://displayatyourownrisk.org/about-dayor/>.

50. See s 32 of the Act.

51. Section 10 of the Act defines 'artistic work' as including a 'photograph'.

52. Sands \& McDougall Pty Ltd v Robinson (1917) 23 CLR 49, 55, 57 (Isaacs J). See also IceTV Pty Ltd v Nine Network Australia Pty Ltd ('IceTV') (2009) 239 CLR 458, 474 [34] (French CJ, Crennan and Kiefel JJ): "There has been a long held assumption in copyright law that "authorship" and "original work" are correlatives; the legislation does not impose double conditions'.

53. IceTV (2009) 239 CLR 458, 474 [33] (French CJ, Crennan and Kiefel JJ).

54. IceTV (2009) 239 CLR 458, 477 [45] (French CJ, Crennan and Kiefel JJ). 
the Act'. ${ }^{55}$ Despite its reference to 'literary nature', this passage does not suggest a higher level of authorial originality for the subsistence of copyright in a literary work than that adopted by the French judgment in IceTV. ${ }^{56}$

The full Court of the Federal Court has held that: "[a]s to the "correlative" relationship between authorship and originality, the contemporary question is simply this: Has the author deployed personal independent skill, labour, intellectual effort, judgement and discrimination in the production of the particular expression of the work? ${ }^{57}$

The Act does not expressly address originality in photographs. It addresses the authorship of photographs, defining 'author', in relation to a photograph, as 'the person who took the photograph' ${ }^{58}$ This is a significant development of earlier legislation which identified the author as the person who owned the negative, ${ }^{59}$ who clearly may have had no involvement in the actual taking of the photograph. Under that earlier model, as Deazley notes, the photograph 'was no longer the product of an author, but simply belonged to a proprietor'. ${ }^{60}$

There is also a dearth of Australian commentary on contemporary photographic originality. ${ }^{61}$ The most extensive discussion is found in Ricketson and Cresswell, ${ }^{62}$ who suggest that the definition of the author of a photograph as the person who 'took' it means that 'it can be argued that the mere taking of the photograph satisfies the correlative requirements of authorship and originality'. ${ }^{63}$ However, while defining the author of a photograph as the person who 'took it' may clarify who materially 'fixes' the work, and is a useful marker of copyright ownership, ${ }^{64}$ it does not necessarily imbue the photograph with originality. As mentioned, photographs are included in the definition of artistic works, and artistic works must be original. ${ }^{65}$ IceTV stressed the 'centrality' of authorship to copyright ${ }^{66}$ and the 'significance' of authorship as the 'essential source' of original works. ${ }^{67}$ In other words, authorship involves more than

55. IceTV (2009) 239 CLR 458, 494 [99], emphasis added.

56. JR Consulting \& Drafting Pty Limited v Cummings [2016] FCAFC 20 (3 March 2016) at [264].

57. Ibid.

58. Section 10(1) of the Act.

59. The Copyright Act 1911 (UK), s 21 provided that the author of the photograph was the 'owner of [the] negative at the time when such negative was made'. This provision is echoed in the definition of 'author' in s 208 of the Act, which applies to photographs taken before the commencement of the Act.

60. R Deazley, 'Struggling with Authority: The Photograph in British Legal History' (2003) 27(3) History of Photography 236, 238.

61. Exceptions include K Bowrey, “"The World Daguerreotyped - What a Spectacle!" Copyright Law, Photography and the Commodification Project of Empire' (May 1, 2012). UNSW Law Research Paper No. 2012-18, available at SSRN: <https://ssrn.com/ abstract $=2060803>$, and K Bowrey, 'Copyright, Photography and Computer Works - the Fiction of an Original Expression' (1995) 18(2) University of New South Wales Law Journal 278.

62. S Ricketson and C Creswell, The Law of Intellectual Property: Copyright, Designs \& Confidential Information (Thomson Reuters, 1 May 2017).

63. Ibid at [7.385]. This is more robustly asserted at para [23.1.610]: 'While a photograph (see [23.1.600]) must be original to qualify for protection, it appears that this is satisfied by the taking of the photograph itself'.

64. Section 35(2) of the Act provides that the author is the owner of the work.

65. Section 32 of the Act.

66. IceTV (2009) 239 CLR 458, [22] and [24] (French CJ, Crennan and Kiefel JJ).

67. IceTV (2009) 239 CLR 458, 493 [96] (Gummow, Hayne and Heydon JJ). 
mere fixation. It must also supply the independent intellectual effort ${ }^{68}$ required by originality.

Ricketson and Cresswell are also troubled by the Act's definition of 'photograph' to mean 'a product of photography or of a process similar to photography, other than an article or thing in which visual images forming part of a cinematograph film have been embodied, and includes a product of xerography, and "photographic" has a corresponding meaning'. ${ }^{69}$ This leads Ricketson and Cresswell to suggest that copyright will subsist in 'a copy of a document made on a machine adapted for the making of copies by a process of xerography, with the consequence that there will be separate protection for every copy which is so made' ${ }^{70}$ However, the mere fact that the statutory definition of a photograph includes a product of xerography says nothing about the originality of the photocopy. The definition defines a photograph, but it doesn't necessarily define an original photograph. It is also questionable, as Ricketson and Cresswell claim, that there is the requisite 'degree of human skill and judgment involved in the ... making of a photocopy, for example, the ... choice of size and shading' ${ }^{71}$ At least with respect to conventional photocopies, as opposed to the genre of photocopier art or 'copigraphy', ${ }^{72}$ the creative choices available to the author would appear to be very limited. I do, however, agree with Ricketson and Cresswell's conclusion that "the humble holiday snapshot, the skilled news photograph and the "high art" photographic composition will receive equal protection as original artistic works'. ${ }^{73}$

Because no Australian case law illuminates originality in photographs, we must extrapolate from the case law on originality generally. We may also consider persuasive authority from other jurisdictions. Where do we locate independent intellectual effort in photography, particularly highly automated modern photography? There are indications in IceTV that the requisite standard of authorial skill and labour is quite low. The French judgment held:

It may be that too much has been made, in the context of subsistence, of the kind of skill and labour which must be expended by an author for a work to be an 'original' work. The requirement of the Act is only that the work originates with an author or joint authors from some independent intellectual effort. ${ }^{74} \ldots$

Much has been written about differing standards of originality in the context of the degree or kind of 'skill and labour' said to be required before a work can be considered an 'original'

68. IceTV (2009) 239 CLR 458, 474 [33] (French CJ, Crennan and Kiefel JJ): 'It is the author or joint authors who bring into existence the work protected by the Act. In that context, originality means that the creation (ie the production) of the work required some independent intellectual effort, but neither literary merit nor novelty or inventiveness as required in patent law'.

69. Section 10(1) of the Act, emphasis added. They also question whether this definition of 'photograph' is broad enough to encompass contemporary means of making photograph-like images that don't involve the chemical action of light, including those produced through digital cameras, radiation or sound. S Ricketson and C Creswell, The Law of Intellectual Property: Copyright, Designs \& Confidential Information (Thomson Reuters, 1 May 2017) [7.380].

70. S Ricketson and C Creswell, The Law of Intellectual Property: Copyright, Designs \& Confidential Information (Thomson Reuters, 1 May 2017) [7.385].

71. Ibid.

72. M Brunet-Weinmann, “Copigraphy: Elements for a Global History” (2003) 22(2) Border Crossings 94.

73. S Ricketson and C Creswell, The Law of Intellectual Property: Copyright, Designs \& Confidential Information (Thomson Reuters, 1 May 2017) [7.385].

74. IceTV (2009) 239 CLR 458, 479 [48] (French CJ, Crennan and Kiefel JJ). 
work in which copyright will subsist. 'Industrious collection' or 'sweat of the brow', on the one hand, and 'creativity', on the other, have been treated as antinomies in some sort of mutually exclusive relationship in the mental processes of an author or joint authors. They are, however, kindred aspects of a mental process which produces an object, a literary work, a particular form of expression which copyright protects. A complex compilation or a narrative history will almost certainly require considerable skill and labour, which involve both 'industrious collection' and 'creativity', in the sense of requiring original productive thought to produce the expression, including selection and arrangement, of the material. ${ }^{75}$

In Telstra Corporation Limited v Phone Directories Company Pty Ltd [2010] FCAFC 149, the Full Court of the Federal Court cited these same aspects of the IceTV judgment, and said:

The dicta in IceTV shift the focus of inquiry away from a concern with the protection of the interests of a party who has contributed labour and expense to the production of a work, to the 'particular form of expression' which is said to constitute an original literary work, and to the requirement of the Act 'that the work originates with an author or joint authors from some independent intellectual effort'. ${ }^{76}$

\section{Bases for originality in photographs}

England's Fine Arts Copyright Act 1862 was the first Anglo-Australian copyright Act to expressly confer copyright on photographs. During the debates on the Fine Arts Copyright Bill 1861, there was concern about conferring copyright on photographs. There was doubt that, as a mere 'mechanical process', ${ }^{77}$ photographs deserved to stand alongside other conventional examples of fine art. There was also a concern about the efficacy of copyright in photographs. Because it was possible for one person to take photographs of the same scene or subject, or even photographs of other photographs, Earl Stanhope was concerned that 'to give a copyright in such cases [was] very likely to occasion dispute and litigation'. ${ }^{78}$ In attempting to allay Earl Stanhope's concerns, Sir Richard Bethell, the Lord Chancellor, said 'it would hardly be possible for two persons to produce representations of the same object under exactly the same conditions of light, position and other circumstances'. ${ }^{79}$ Without knowing it, Bethell articulated some of the essential foundations of what, today, are considered important sources of photographic originality in choices relating to light, position and 'other circumstances'.

The first UK decision to consider authorship of photographs was Nottage $v$ Jackson. ${ }^{80}$ This case concerned a photograph of the Australian cricket team which

75. IceTV (2009) 239 CLR 458, 478 [47] (French CJ, Crennan and Kiefel JJ).

76. Telstra Corporation Limited v Phone Directories Company Pty Ltd [2010] FCAFC 149, [82] (Keane CJ, Perram and Yates JJ).

77. Hansard, 3rd Series, v.165, 1890-91, Parliamentary Debates on the Fine Art Copyright Act (20 March), London (1862), Primary Sources on Copyright (1450-1900), L Bently and M Kretschmer (eds) <www.copyrighthistory.org>.

78. Hansard, 3rd Series, v.165, 2016-17, Parliamentary Debates on the Fine Art Copyright Act (22 May), London (1862), Primary Sources on Copyright (1450-1900), L Bently and M Kretschmer (eds) <www.copyrighthistory.org >.

79. Hansard, 3rd Series, v.165, 2019, Parliamentary Debates on the Fine Art Copyright Act (22 May), London (1862), Primary Sources on Copyright (1450-1900), L Bently and M Kretschmer (eds) <www.copyrighthistory.org>.

80. Nottage v Jackson (1883) 9 QB 627. 
had been taken by an employee of Nottage, a photographic firm. Jackson had copied the photograph, and Nottage sued for infringement. Jackson's defence was predicated on the inaccurate registration of Nottage's photograph under the registration system of the time, which recorded Nottage and his partner as the authors, when in fact it was their employee who took the photograph. The court had to consider the novel question of who was, indeed, the author of the photograph. Lord Brett suggested that the author of a photograph was:

the person who effectively is as near as he can be, the cause of the picture which is produced, that is, the person who superintended the arrangement, who has actually formed the picture by putting people into position, and arranging the place in which the people are to be - the man who is the effective cause of that. ${ }^{81}$

Lord Justice Bowen considered that the author was the person who "is most nearly the effective cause of the representation when completed'. ${ }^{82}$ He also attempted to define the author of a photograph by a process of exclusion:

It is evidently not the man who pays - not the man who contributes the machinery - not the man who does nothing except form the idea - not the man who does nothing towards embodying the idea - not the man who finances the expedition, or who sends it out - none of these persons, in the ordinary sense of the term, can be considered the artist. ${ }^{83}$

In the seminal US Supreme Court decision Burrow-Giles Lithographic Co. v Sarony, ${ }^{84}$ the court clarified that photographs can be an original work of art. In Sarony's picture of Oscar Wilde, the photographer's intellectual effort could be discerned in 'selecting and arranging the costume, draperies, and other various accessories in said photograph, arranging the subject so as to present graceful outlines, arranging and disposing the light and shade, suggesting and evoking the desired expression'. ${ }^{85}$

While US law can only be persuasive in Australian courts, note that the court's judgment in Burrow-Giles is redolent of IceTV's stipulation that authorship involves 'intellectual effort' when it declared that the US Constitution 'is broad enough to cover an act authorizing copyright of photographs, so far as they are representatives of original intellectual conceptions of the author' ${ }^{86}$ At photography's dawn and during its early development, there was scepticism about its status as authored art, due to its mechanistic processes and the facsimile reproduction of its subject matter. ${ }^{87}$ However, early Australian Parliamentary debates also recorded those who insisted that photography required 'the application of brain power', ${ }^{88}$ and that 'there is as much intelligence required in taking a photograph as there is in any other avocation'. ${ }^{89}$

81. Ibid, 630-31. Nottage was followed in Woodman v Raphael Tuck \& Sons (1887) 53, 57, where Sterling J considered that the author of a photograph was the person who 'superintended the arrangements and actually formed the picture'.

82. Nottage (1883), 632.

83. Ibid.

84. Burrow-Giles Lithographic Co. v Sarony, 111 U.S. 53 (1884).

85. Ibid, 55.

86. Ibid, 58, emphasis added.

87. K Bowrey, 'Copyright, Photography and Computer Works - the Fiction of an Original Expression' (1995) 18(2) University of New South Wales Law Journal 278, 283.

88. Australia, House of Representatives 1905, debates, vol HR30, p 7248 (Mr Fisher), quoted in K Bowrey, 'Copyright, Photography and Computer Works - the Fiction of an Original Expression' (1995) 18(2) University of New South Wales Law Journal 278, 285.

89. Ibid. 
Since these early decisions, originality has been identified in all steps of the photographic procedure, with case law across a number of jurisdictions confirming the capacious potential for locating originality in photography.

Activities antecedent to taking the photograph itself may qualify, such as selecting location, props, costumes and posing the subject, as exemplified in Burrow-Giles ${ }^{90}$ and Gross v Seligman, ${ }^{91}$ in which copyright was held to subsist in a photograph of a model posed in a particular way. ${ }^{92}$ Soon after Burrow-Giles, US courts expanded the basis for originality beyond pre-shoot staging, recognizing the first unstaged 'point and shoot' originality in the 1897 case of Bolles v Outing Co. ${ }^{93}$ which involved a photograph of a yacht. Thus in the actual execution of the photograph (what the United States District Court has referred to as 'originality in the rendition'), ${ }^{94}$ originality can be discerned in the photographer's creative choices in framing the shot, focusing, timing, angle, lighting, exposure and filters. Rogers $v$ Koons ${ }^{95}$ concerned a photograph of two people holding eight German Shepherd puppies, and is a good example of both antecedent ${ }^{96}$ and rendition originality. ${ }^{97}$ So is Mannion v Coors Brewing Co. ${ }^{98}$ which depicted a celebrity against a cloudy sky backdrop at an acute angle. The court found originality in the photographer's 'relatively unusual angle and distinctive lighting', but also in his 'posing man against sky' and his instruction to the celebrity 'to wear simple and plain clothing and as much jewelry as possible, and "to look "chilled out". 99 Rendition originality can extend even to static subjects, like landscape and city scenes. In Temple Island $v$ New English Teas and Nicholas John Houghton ${ }^{100}$ for example, copyright was held to subsist in a black and white photograph of a red bus travelling across Westminster Bridge. The court held that '[a] photograph ... can have the character of an artistic work in terms of copyright law if the task of taking the photograph leaves ample room for an individual arrangement. What is decisive are the arrangements (motif, visual angle, illumination, etc.) selected by the photographer himself or herself'. ${ }^{101}$ Finally, post-production creative choices may include modifying the composition by cropping, colour and tone manipulation and (today) a host of digital editing techniques. In Painer $v$ Standard Verlags $^{102}$ the question was whether the photographic portrait of a woman was an

90. For example, Burrow-Giles Lithographic Co. v Sarony, 111 U.S. 53 (1884).

91. Gross v Seligman 212 F. 930 (2d Cir. 1914).

92. Conversely, antecedent originality will be lacking if the posing was done by the subject, rather than the photographer. This was the case in Harney $v$ Sony Pictures Television, Inc., 704 F.3d 173, 184 (1st Cir. 2013) where the court held that Harney's 'creation consist[ed] primarily of subject matter - "facts" - that he had no role in creating, including the central element of the Photo: the daughter riding piggyback on her father's shoulders'.

93. Bolles v Outing Co. 77 F. 966 (2d Cir. 1897), aff'd, 175 U.S. 262 (1899).

94. Mannion v Coors Brewing Co., 377 F.Supp. 2d 444, 452 (2005).

95. Rogers $v$ Koons 960 F.2d 301(2d Cir. 1992).

96. Ibid, 307: 'Elements of originality in a photograph may include posing the subjects ... selection of film and camera [and] evoking the desired expression'.

97. Rogers $v$ Koons 960 F.2d 301, 307 (2d Cir. 1992): 'Elements of originality in a photograph may include ... lighting, angle ... and almost any other variant involved'.

98. Mannion v Coors Brewing Co. 377 F.Supp. 2d 444 (S.D.N.Y. 2005).

99. Ibid, 455 .

100. Temple Island v New English Teas and Nicholas John Houghton (Temple Island) [2012] EWPCC 1.

101. Ibid, at s 20 .

102. Painer v Standard Verlags (C-145/10) EU:C:2011:798; [2012] E.C.D.R. 6. 
original photograph under EU law. EU law mandates copyright protection for '[p]hotographs which are original in the sense that they are the author's own intellectual creation', ${ }^{103}$ and an original work is the 'author's own intellectual creation reflecting his personality'. ${ }^{104}$ In Painer, the CJEU held that copyright in a photograph subsists if 'the author was able to express his creative abilities in the production of the work by making free and creative choices'. In addition to recognizing antecedent creative choices, ${ }^{105}$ and rendition originality, ${ }^{106}$ the court acknowledged that postproduction choices may be creative. ${ }^{107}$

The formulation of the originality standard in these US, UK and European cases is perfectly consistent with authorial claims made by photographers for centuries:

Up to and including the instant of exposure, the photographer is working in an undeniably subjective way. By his choice of technical approach (which is a tool of emotional control), by his selection of the subject matter to be held within the confines of his negative area, and by his decision as to the exact, climatic [sic] instant of exposure, he is blending the variables of interpretation into an emotional whole which will be a basis for the formation of opinions by the viewing public. ${ }^{108}$

And in the words of photographer Edward Weston:

By varying the position of his camera, his camera angle, or the focal length of his lens, the photographer can achieve an infinite number of varied compositions with a single, stationary subject. By changing the light on the subject, or by using a color filter, any or all of the values in the subject can be altered. By varying the length of exposure, the kind of emulsion, the method of developing, the photographer can vary the registering of relative values in the negative. And the relative values as registered in the negative can be further modified by allowing more or less light to affect certain parts of the image in printing. Thus, within the limits of his medium, without resorting to any method of control that is not photographic (i.e., of an optical or chemical nature), the photographer can depart from literal recording to whatever extent he chooses. ${ }^{109}$

Thus from the modest location of originality in antecedent scene arrangement in Burrow-Giles, it is now possible to find photographic originality in 'almost any ... variant' ${ }^{110}$ and a lack of originality is likely to be 'an extremely unusual circumstance'. ${ }^{111}$

103. Art 6 of the Copyright Term Directive (93/98/EEC).

104. Preamble, Copyright Term Directive.

105. 'In the preparation phase, the photographer can choose the background, the subject's pose and the lighting', Painer v Standard Verlags (C-145/10) EU:C:2011:798; [2012] E.C.D.R. 6, at [91].

106. Ibid.

107. Ibid: 'Finally, when selecting the snapshot, the photographer may choose from a variety of developing techniques the one he wishes to adopt or, where appropriate, use computer software'. 108. WE Smith, 'Photographic Journalism', Photo Notes, June 1948, at 4, reprinted in N Lyons (ed), Photographers On Photography 103, 104 (1966), cited in Ets-Hokin v Skyy Spirits, Inc. Ninth Circuit 225 F.3d 1068, 1073-4 (2000).

109. E Weston, 'Seeing Photographically', 9 Complete Photographer 3200, 3203 (WD Morgan ed., 1943), reprinted in N Lyons (ed), Photographers On Photography (1966), at 159, 161, cited in Ets-Hokin v Skyy Spirits, Inc. Ninth Circuit 225 F.3d 1068, 1073-4 (2000).

110. Rogers $v$ Koons 960 F.2d 301, 307 (2d Cir. 1992).

111. Mannion v Coors Brewing Co. 377 F.Supp. 2d 444, 452 (S.D.N.Y. 2005). 


\section{Photographs of two-dimensional cultural objects and originality}

We return to the important question pursued in this article, which relates to the copyright status of faithful photographs of two-dimensional art housed in Australia's cultural institutions. Based on the above survey of photographic originality, while a photographer's imaginative choices appear extensive, what creative choices are made by photographers of these items? In the photographer's attempt to faithfully replicate the features of the photographed item, do they effectively hobble their creativity, and correspondingly vitiate any basis for originality?

No Australian authority has considered the issue of slavish photographic reproductions of two-dimensional art. In Interlego AG v Croner Trading Pty Ltd, a draughtsman had copied an earlier drawing of a Lego brick, and it was alleged that this was slavish copying and that the second drawing therefore lacked originality. The full Court of the Federal Court rejected the argument, being satisfied that the draughtsman had used a different scale and made some small changes to the appearance of the Lego brick in his rendition. ${ }^{112}$ There was a different result in the UK version of this litigation, where the changes were considered too miniscule to render the second drawing anything but an unoriginal copy. ${ }^{113}$ Lord Oliver held that:

Originality in the context of literary copyright has been said ... to depend upon the degree of skill, labour and judgment involved in preparing a compilation ... to apply that ... as a universal test of originality in all copyright cases is ... palpably erroneous ... Skill, labour or judgment merely in the process of copying cannot confer originality. ${ }^{114}$

In the absence of any Australian authority directly on point, what have other jurisdictions decided? Very few decisions have dealt specifically with the question of whether slavish photographic reproductions of two-dimensional art meet the requisite standard of originality. A chronological survey of those few decisions follows.

In the 1869 English Graves' Case,${ }^{115}$ Graves owned the copyright in a number of paintings, from which he commissioned engravings. He took photographs of the engravings, and the defendant copied the photographs. The defendant argued that the photographs lacked originality, being simple reproductions of existing engravings. In response, Justice Blackburn stated:

[I]t has been argued that the word 'original' is to be taken as applying to the word photograph. The distinction between an original painting and its copy is well understood, but it is difficult to say what can be meant by an original photograph. All photographs are copies of some object, such as a painting or a statue. And it seems to me that a photograph taken from a picture is an original photograph, in so far that to copy it is an infringement of this [copyright] statute. ${ }^{116}$

This apparently acknowledges that photographs of engravings are original. However, Graves lacks contemporary persuasiveness for a number of reasons. Justice Blackburn's brief comment lacks explanation and coherence. It is by no means clear that the distinction between an original painting and its copy is 'well understood'. Indeed, it is very difficult to discern a distinction between the two, particularly when

112. Interlego AG and Lego Australia Pty Ltd v Croner Trading Pty Ltd [1992] FCA 624; (1992) 111 ALR 597 (1992) 25 IPR 65, [108] (Gummow J).

113. Interlego AG v Tyco Industries Inc. [1988] RPC 343.

114. Ibid, 371.

115. Graves' Case (1869) L.R. 4 Q.B. 715.

116. Ibid, 723. 
the 'copy' of the painting is the perfect facsimile achieved by a photograph. If the copy of the painting is a reproductive engraving then it is perhaps easier to perceive the distinction, since the fine, manually wrought lines of an engraving exhibit more of the creative choices of the engraver, and do not mimic the perfect duplicate of a photograph. In Newton $v$ Cowie,${ }^{117}$ Best CJ explained how ' $[\mathrm{t}]$ he engraver, although a copyist, produces the resemblance by means very different from the painter or draughtsman from whom he copies; means which require great labour and talent'. ${ }^{118}$ In Graves, the photographs were of engravings made for Graves, in which he owned copyright. The photographs of the engravings were taken by a Mr Spencer, and an agreement between Spencer and Graves reserved the copyright in the photographs to Graves. ${ }^{119}$ Thus the agreement reflects an untested assumption that Spencer had copyright to assign. This may have influenced the court's conclusion that there was, indeed, copyright in Spencer's photographs.

In Graves, Justice Blackburn's most persuasive comment is his concession that 'it is difficult to say what can be meant by an original photograph', since this at least acknowledges the objective dissonance between photography's impeccable reproducibility and originality. It also more accurately acknowledges the novelty of the photograph as copyright subject matter. Graves was decided a mere six years after photographs became a recognized copyright work, and long before any serious judicial consideration of how still nascent concepts of originality might be applied to this novel art form. It reflects a 'sweat of the brow' concept of originality which has little contemporary relevance. MacGillivray in 1902 cited Graves as authority for the proposition that 'the execution may be original but not the design, as in the case of a photograph of an old picture'. ${ }^{120}$

During one of the many attempts to introduce a bill to consolidate and better organize the piecemeal copyright legislation in nineteenth-century England, solicitor Herbert Bentwich gave evidence before a select committee that 'there should be a distinction between photographs and ordinary works of art or works of fine art as described in the bill', but argued for an exception for 'photographs which are reproductions of original works of fine art', which 'should have the same protection of the original works'. ${ }^{121}$ This reflects earlier draft provisions of the Berne Convention of 1886, which provided that '[i]t is understood that an authorised photograph of a protected work of art shall enjoy legal protection ... for the same period as the principal right of reproduction of the work subsists .... ${ }^{122}$ This provision, although silent on the originality of the photograph, recognized the essential foundation of protecting the photographic copy of a painting, engraving or drawing, which facilitated a vibrant

117. Newton v Cowie [1827] 4 Bing 234, 130 ER 759.

118. Newton v Cowie [1827] 4 Bing 234, 245-6.

119. Graves' Case (1869) L.R. 4 Q.B. 715, 717.

120. EJ MacGillivray, A Treatise Upon the Law of Copyright in the United Kingdom and the Dominions of the Crown, and in the United States of America (John Murray 1902), Chapter VIII, section 1, emphasis added.

121. Report of the Select Committee of the House of Lords, Session Papers 1899, v.8, 3111-13, cited in R Deazley, 'Struggling with Authority: The Photograph in British Legal History' (2003) 27(3) History of Photography 236, fn 72.

122. The Closing Protocol of the 1885 draft of the Berne Convention, Actes de le 2 me Conférence internationale Pour La Protection Des Oeuvres Littéraires et Artistiques Réunie à Berne du 7 au 18 Septembre 1885, in S Ricketson, The Berne Convention 1886-1986 P 6.33 (1987), cited in J Ginsburg, 'The Concept of Authorship in Comparative Copyright Law' (2003) 52 De Paul Law Review 1063, fn 83. 
nineteenth-century industry in the dissemination of images of artworks. It also may reflect the sentiment that underscores the contemporary proprietary claims by cultural institutions to photographs of public domain works.

This objective of protecting commercial interests probably explains the puzzling circular logic of Justice Blackburn in Graves' Case, when he said 'it seems to me that a photograph taken from a picture is an original photograph, in so far as to copy it is an infringement of this statute'. ${ }^{123} \mathrm{He}$ wanted to find an infringement in order to protect the engravings, themselves made from paintings, and therefore the photographs were original. As already mentioned, there was no explanation of the source of this originality.

In Burrow-Giles, the court considered the defendant's argument that photography was a mere mechanical process, 'with no place for novelty, invention, or originality', ${ }^{124}$ and that it was 'simply the manual operation, by the use of these instruments and preparations, of transferring to the plate the visible representation of some existing object, the accuracy of this representation being its highest merit'. ${ }^{125}$ The court stated that ' $[\mathrm{t}] \mathrm{his}$ may be true in regard to the ordinary production of a photograph, and that in such case a copyright is no protection. On the question as thus stated we decide nothing'. ${ }^{126}$ Thus we have no guidance from the court as to what may constitute the 'ordinary production of a photograph', and how to separate such an 'ordinary' creation from an original photograph. But the judgment hints that mere manual operation designed to achieve an optimal degree of 'accuracy of representation' would fail to satisfy the originality threshold. This seems to be a perfect description of faithful photographs of two-dimensional artworks.

In Robinson v Sands \& McDougall Pty Ltd, ${ }^{127}$ Barton J cited Graves' Case and Blackburn J's oft-cited judgment, and concluded with the proposition that '[n]o doubt a photograph copied from the original photograph could not claim copyright, but that stands on a different footing from the original photograph'. ${ }^{128}$ This clearly recognizes that there is no originality in a facsimile photographic reproduction of a photograph. If copyright cannot subsist in a photograph of a photograph, it is difficult to discern a difference in the photographer's creative choices between a photograph of a photograph, and a photograph of a painting.

Bridgeman Art Library, Ltd. v Corel Corp ${ }^{129}$ is the most relevant authority on the issue. In Bridgeman, the District Court for the Southern District of New York held that faithful photographs of public domain paintings were not original. Bridgeman, a United Kingdom company, acquired photographs of public domain works of art and licensed their reproduction. It claimed copyright in those photographs, and alleged that Corel wrongfully copied a number of them. Summary judgment was entered for Corel on the grounds that copyright did not subsist in Bridgeman's images. ${ }^{130}$ Bridgeman successfully moved for re-argument and reconsideration, but again judgment was entered against it, for the same, but more elaborately explained, reasons.

123. Graves' Case (1869) L.R. 4 Q.B. 715, 723.

124. Burrow-Giles Lithographic Co. v Sarony, 111 U.S. 53, 59 (1884).

125. Ibid.

126. Ibid, emphasis added.

127. Robinson v Sands \& McDougall Pty Ltd (1916) 22 CLR 124.

128. Ibid, 132 (Barton J).

129. Bridgeman Art Library, Ltd v Corel Corp. ('Bridgeman II') 36 F. Supp. 2d 191, 196 (S.D.N.Y. 1999).

130. Bridgeman Art Library, Ltd v Corel Corp. 25 F. Supp. 2d 421, 426 (S.D.N.Y. 1998). 
The court noted that there is broad scope for copyright in photographs because 'a very modest expression of personality will constitute sufficient originality', however, it cited Nimmer's argument that copyright is not available 'where a photograph of a photograph or other printed matter is made that amounts to nothing more than slavish copying'. The court cited previous authority demanding a 'distinguishable variation' ${ }^{131}$ or 'genuine difference' ${ }^{132}$ between the photograph and the original, which Bridgeman's photographs lacked, and confirmed that this could not be supplied simply by a change of medium. ${ }^{133}$ Thus there was no 'distinguishable variation' between the textured three-dimensional form of the photographed painting, and the flat two-dimensional photographic echo. Because Bridgeman's photographs were " slavish copies" of public domain works of art' 134 and 'the point of the exercise was to reproduce the underlying works with absolute fidelity', ${ }^{135}$ this meant that 'there was no spark of originality' ${ }^{136}$ in them. Bridgeman provided no evidence of the creative choices of its photographers. Had the court heard directly from the Bridgeman photographers, would they have explained how the imperative to mirror reality was driven by technical and commercial objectives, but was nevertheless tempered and shaped by subjective, if subtle, choices of taste? How persuasively would they have rejected John Lewis and Edwin Smith's assertion that, when photographing paintings, '[m] ost forms of photography involve choice, at least of a view-point, of lighting and of exposure. Here there is none'. ${ }^{137}$

Bridgeman's argument for originality may have been strengthened if it could have demonstrated that the photographs had been edited to, for example, 'cure' defects in the original painting or photograph, such as fading, stains, creases or damage. But again, there was no evidence of that kind of modification. Likewise, originality may have been established if Bridgeman could have demonstrated that different photographers would produce different photographic reproductions of the same painting (presumably through the exercise of different choices), but no such evidence was tendered in Bridgeman. When Basil Field gave evidence to the 1878 UK Royal Commission into Copyright, he argued:

... a photograph has no design, there is no imagination or feeling in it. If you put two photographers with their boxes before the same subject, they will produce exactly the same result; but if you put three or four different artists before the same subject, they will produce results totally differing from one another, although all may be equally true to nature. ${ }^{138}$

One leading copyright scholar has argued that 'if the nature of the task does not ineluctably determine the manner in which the putative author executes the work, then she is making choices that are subjective and most likely minimally creative, even if she

\section{Bridgeman II, 196 (n 129).}

132. Ibid.

133. Ibid (quoting Past Pluto Prod. v Dana, 627 F. Supp. 1435, 1441 (S.D.N.Y. 1986)).

134. Ibid, 197.

135. Ibid.

136. Ibid.

137. J Lewis and E Smith, The Graphic Reproduction and Photography of Works of Art (1969), cited in G Petri, 'The Public Domain vs. the Museum: The Limits of Copyright and Reproductions of Two-dimensional Works of Art' (2014) 12(1) Journal of Conservation and Museum Studies Art. 8.

138. The Royal Commissions and the Report of the Commissioners: Copyright Commission, Session Papers, 1878, v.24, 3620, cited in R Deazley, 'Struggling with Authority: The Photograph in British Legal History' (2003) 27(3) History of Photography 236, 238. 
intends to enable the first author's vision to direct her own'. ${ }^{139}$ It was incumbent on Bridgeman to identify the choices that left their photographers' personal stamp on the photographs, and this evidence was simply missing. In other words, photographers must do more than point to the decisions they made, they must show how those decisions altered the reality of the photographed painting or photograph. We must be able to discern the trace of their intellectual effort in the photograph. It is not enough, as others have suggested, that it takes 'human skill and labour to produce a good photograph'. ${ }^{140}$ While the Bridgeman court conceded that Bridgeman's photography 'doubtless requir[ed] technical skill and effort', ${ }^{141}$ the mechanical skill and effort involved in the process of making a faithful copy cannot confer originality under the law of the USA, ${ }^{142}$ the UK, ${ }^{143}$ or Australia. ${ }^{144}$ The objective of faithfully reproducing the painting as accurately as possible eliminates a number of choices that might otherwise have been available. For example, if an oil painting is shot outside, it may be unevenly lit, or glare might be caused by sunny reflections on its shiny surface, forcing the photographer inside. After a shot is taken, the photograph may be manipulated to more faithfully reflect the true colours of the original. But notably, these choices and modifications are designed to move closer to the original reality of the painting, not to add any material variation to it. They are designed to recreate the original expression, not create new expression.

Bridgeman is consistent with Australian originality doctrine. The distinguishable variation or genuine difference demanded under Bridgeman is equivalent to the evidence of the author's intellectual effort emerging in the particular expression of the work demanded under IceTV. ${ }^{145}$ It seems unavoidable that in these faithful photographic reproductions of paintings or photographs, the expressive value of the photographer cannot be detected, and that the true expressive value in the photograph inheres exclusively in the photographed subject matter, created by an antecedent author. An important policy imperative compels this conclusion. If copyright is conferred on such photographs based only on the technical skill in accurately reproducing the subject matter, then photographers of public domain works could perpetually restart the copyright term by taking a new photograph of the artwork as each copyright term expires.

In Antiquesportfolio.com.plc v Rodney Fitch \& Co, ${ }^{146}$ Neuberger J considered, but did not decide, whether copyright could subsist in a 'purely representational photograph

139. J Ginsburg, 'The Concept of Authorship in Comparative Copyright Law' (2002) 52 DePaul Law Review 1063, 1085.

140. K Garnett, 'Copyright in Photographs' (2000) European Intellectual Property Review 229, 234.

141. Bridgeman II, 197 (n 129).

142. Feist Publ'ns v Rural Tel. Serv. Co., Inc., 499 U.S. 340 (1991).

143. Interlego AG v Tyco Industries Inc. [1988] RPC 343, 371 (Lord Oliver): ‘[o]riginality in the context of literary copyright has been said ... to depend upon the degree of skill, labour and judgment involved in preparing a compilation ... to apply that ... as a universal test of originality in all copyright cases is ... palpably erroneous ... Skill, labour or judgment merely in the process of copying cannot confer originality'.

144. IceTV Pty Ltd v Nine Network Australia Pty Ltd ('IceTV') (2009) 239 CLR 458, 472 [28] (French CJ, Crennan and Kiefel JJ: 'Copyright is not given to reward work distinct from the production of a particular form of expression'.

145. Ibid, 479 [48] (French CJ, Crennan and Kiefel JJ).

146. Antiquesportfolio.com v Rodney Fitch [2001] F.S.R. 345 (Ch D). 
of a two-dimensional object such as a photograph or a painting'. ${ }^{147}$ He said 'if the photographer in such a case could show that he had in fact used some degree of skill and care in taking the photograph, he could claim originality in, and, therefore, intellectual property rights in respect of, such a photograph'. ${ }^{148}$ Notably, Neuberger J did not articulate examples of how the requisite 'skill and care' could be demonstrated in such a case. For the reasons articulated above, creative choices which can be discerned in the photograph are likely not to exist.

\section{Photographs of three-dimensional cultural objects and originality}

Some of the photographs of public domain cultural objects are of three-dimensional objects such as sculptures. There is greater scope for demonstrating originality in the case of these photographs, due to the increased creative choices available to the photographer of a three-dimensional object. Unlike two-dimensional objects, photographers can literally circle around three-dimensional objects, making numerous and complex selections of angle, point of view, framing, positioning and lighting. ${ }^{149}$ The variety of choices available to such photographers is exemplified well in the 2010 MOMA exhibition, The Original Copy: Photography of Sculpture, 1839 to Today, ${ }^{150}$ the introduction to which noted that '[t]hrough crop, focus, angle of view, degree of close-up, and lighting, as well as techniques of darkroom manipulation, collage, montage, and assemblage, photographers have not only interpreted sculpture but created stunning reinventions of it'. ${ }^{151}$

This means that copyright is likely to subsist in photographs of three-dimensional objects. This would have apparently deleterious effects if the photographed object is in the public domain, effectively removing the object from the public domain through the proxy of the photograph. This may not be problematic if alternative photographers have access to the cultural objects and can take their own photographs, exhibiting their own creative choices and generating independent copyright in the photograph of the object. However, as discussed below, this is dependent on gaining access to the object in the possession of the cultural institutions and being permitted to take a photograph of it, which is not always a straightforward option. Most public domain works are not, in fact, in the public domain. They are locked in private spaces. Even if they are in public institutions, we can only access them if we can access the institution, or gain access to a digital surrogate of the work.

\section{PART 3: CONTROL OUTSIDE OF COPYRIGHT}

The above discussion has demonstrated that copyright is likely to subsist in photographs of three-dimensional objects, but not faithful reproductions of two-dimensional

147. Ibid, 353 [33].

148. Ibid, 353 [35].

149. See ibid, 353-4 [36-8], in which Neuberger J held that a photograph of a static threedimensional object, such as a piece of furniture, was protected by copyright, because the photographer would exhibit some skill and effort in terms of positioning, angle, lighting and focus, and in the exhibition of particular features of the photographed object, such as the colour, and details of the items. The photographer may also have demonstrated skill in choosing the particular item as an exemplar of its type.

150. Museum of Modern Art <https://www.moma.org/interactives/exhibitions/2010/original copy/>.

151. Ibid. 
objects. This means that the implied authority to control digital images under copyright, discussed in Part 1, is illusory in the case of the photographs of two-dimensional objects. However, galleries also foster the perception of legitimate authority through contract, and through real and chattel property rights.

\section{The licensing schemes}

Almost all of the galleries reviewed for the purpose of this article conduct schemes under which they license digital images of artworks in their collections. ${ }^{152}$ Usually, the quality of the image differs, depending on the proposed use, ${ }^{153}$ as does the price. ${ }^{154}$ Revenue from these schemes no doubt supports galleries in fulfilling their mandates.

As mentioned above, the gallery websites are peppered with nomenclature that either implies copyright ownership ("contravention is an infringement of Australia's Copyright Act 1968'), or evokes copyright-like rights ('reproduction', 'copy', 'licence'). This suggests a tendency to conflate the effects of copyright and contract. Infringing galleries' terms and conditions may attract liability for breach of contract, ${ }^{155}$ but not copyright infringement. Galleries also apparently assume that their contractual terms can override copyright exceptions, and/or 'create' copyright in unoriginal works, an assumption which may not be well founded. ${ }^{156}$ Perhaps the more worrying effect of galleries' terms of adhesion is the issue of contract effectively rebooting copyright in public domain works, or at least conferring a copyright-like control.

Non-copyright experts would be forgiven for believing assertions of copyright. Copyright amateurs would not understand that copyright's originality standard generally denies copyright in a slavish photographic reproduction of a two-dimensional work. Even copyright experts would be forgiven for acceding to copyright claims. For example, while copyright will not subsist in a slavish photographic reproduction

152. See, for example, the Art Gallery of New South Wales: 'The Art Gallery of NSW licenses digital images of artworks in our collection for online and print publishing as well as some commercial products. Prints of many works in the collection, and other merchandise, can be purchased through our Gallery Shop', <https://www.artgallery.nsw.gov.au/research/artwork/usingimages-of-the-collection>.

153. See, for example, the Art Gallery of New South Wales:

File types we supply:

- For publications and products: high-resolution 300dpi digital files

- For multimedia, internet/intranet and email newsletters: low-resolution 72dpi digital files

- For research or study: low-resolution 72dpi JPEG files or PowerPoint files.

$<$ https://www.artgallery.nsw.gov.au/research/artwork/using-images-of-the-collection/>.

154. For example, the Art Gallery of New South Wales stipulates that: 'Fees are structured on the use and market for the publication or product ... Charges may vary depending on order. A high-resolution publication-quality digital image supplied electronically is $\$ 150$ plus GST ... For publications and products, a usage fee is charged, dependent on print run and the nature of the proposed market. Concessions may be available in certain situations', <https://www.artgallery.nsw.gov.au/research/artwork/using-images-of-the-collection/>.

155. And note that privity of contract would limit the galleries' right of action against the party in breach, rather than downstream users who had gained access to the image through the breaching party.

156. See Commonwealth of Australia, Copyright Law Review Committee, Copyright and Contract (2002), para 7.04: 'the enforceability of contracts purporting to exclude or modify the copyright exceptions is unsettled as a matter of domestic law'. 
of a two-dimensional artwork, how can this be reliably determined without the opportunity to compare the two-dimensional artwork and the photograph? The originality standards in copyright law are notoriously murky, which can lead to genuine, if misconceived, claims of copyright ownership.

An established market in the licensing of copies of public domain works entrenches the illusion of rights. The dispute between Getty Images and photographer Carol Highsmith demonstrates how the mere practice of licensing combined with a poor understanding of copyright law, or the particular circumstances relating to an artwork, can cement a copyright-like system of propertization. In late December 2015, photographer Carol Highsmith received a threat from License Compliance Services (LCS) on behalf of Alamy, a Getty-affiliated company. She was alleged to have used an image represented by Alamy on her website, without the requisite licence, and this was alleged to have constituted copyright infringement. ${ }^{157}$ Liability could be avoided by paying the licence fee of $\$ 120$. Unbeknownst to LCS, the image was in fact Highsmith's, and was one of many thousands of images Highsmith had previously donated to the Library of Congress and made available to the public to reproduce and display for free. Unfortunately for Highsmith, that largesse extended to Getty, and there was no legal restriction on it setting up a business model for the licensing of the image.

The difficulty here is that most people receiving a similar invoice would have no basis for knowing that Highsmith had gifted her copyright works to the public domain, and that there was no copyright basis to Getty's claim. There is a tendency to acquiesce in claims of copyright, particularly from a licensing machine like Getty Images, and particularly when the recipient of the claim has a poor understanding of copyright law. Why would a licence fee be demanded unless there was some basis for the demand? All of this normalizes the propertization of the digital proxies and leads to a 'feedback loop" ${ }^{158}$ in which a right to claim a licence fee is asserted, that demand is acquiesced to and the licence fee is paid, establishing or proving the existence of a 'legitimate' market, which itself feeds back into the loop and tends to legitimize complementary copyright claims.

\section{Contractual and other restrictions on photography}

It might be thought that those seeking access to digital reproductions of the cultural objects housed by Australia's galleries could take their own photographs and thereby avoid any copyright claims or licensing fees. The practical difficulties with this option include the need to travel to the relevant gallery, and the fact that the vast majority of items in galleries are not on display and capable of being photographed. As the physical custodian of the cultural objects, the real estate in which they are housed, and the digital files of the photographic proxies, galleries have powerful property rights which may restrict access to the cultural object. Ultimately, access to cultural materials, whether in physical or digital form, is at the discretion of the gallery.

Galleries may also impose restrictions on the taking of photographs which limit the use which can be made of the photographs, and arguably, the quality of the

157. Carol M. Highsmith v Getty Images (US), Inc, complaint, case no. 16 CIV. 5924, United States District Court Southern District of New York, available at <http://digitalcommons.law. scu.edu/cgi/viewcontent.cgi?article $=2265 \&$ context=historical $>$.

158. J Gibson, 'Risk Aversion and Rights Accretion in Intellectual Property Law' (2007) 116 Yale Law Journal 882. 
photographs. All of the galleries surveyed for this article permit visitors to take photographs in non-restricted areas, but only for personal use, banning commercial photography. In most cases tripods, flash or additional lighting is not permitted, ${ }^{159}$ which may compromise the quality of the photograph. AGWA and the National Gallery of Victoria also purport to restrict downstream reproductions and displays on personal websites. AGWA's policy states:

Visitors are permitted to take photographs with hand-held devices in non-restricted public areas within the Art Gallery of Western Australia for personal use only. The use of tripods, flash or additional lighting is not permitted. Images photographed under this policy cannot be reproduced, displayed on personal websites, or used commercially. ${ }^{160}$

The National Gallery of Victoria has a very similar policy to that of AGWA. ${ }^{161}$

Ordinarily, if copyright subsists in a photograph, ${ }^{162}$ the owner of the copyright enjoys the full extent of copyright's exclusive rights, including the right to reproduce and communicate the photograph. Clearly there is an attempt here to exert downstream control and limit any copyright rights in the photograph through contract, ${ }^{163}$ since there is no basis for prohibiting reproduction on personal websites through any other means. The galleries are likely attempting to avoid liability for authorizing visitors' further infringing reproductions where photographs of copyright works have been taken. However, it is extremely unlikely that galleries will be authorizers without having the requisite means of controlling visitors' downstream conduct, ${ }^{164}$ and if they were to be authorizers, the most likely basis for liability would be their permitting visitors to take infringing photographs in the first place.

159. See, eg, the Art Gallery of NSW: 'You are welcome to take photographs, except if a specific artwork or exhibition has a sign indicating no photography. Check with one of the uniformed Gallery officers if in doubt. Please help protect the art by not using flash, tripods or monopods. You need to make a written request if you intend to photograph or film for publication or commercial purposes. For more information and contact details, see Image reproduction', $<$ https://www.artgallery.nsw.gov.au/visit-us/plan-your-visit/faq/\#faq-1>. See also The Art Gallery of South Australia: 'The Art Gallery of South Australia allows still photography for personal use only, using hand-held cameras in non-restricted areas. The use of flash or video cameras is prohibited ... Applications for commercial photography, photography in restricted areas, filming or use of additional equipment, must be made in writing to the Publications Officer: Image Sales \& Rights. Fees and conditions may apply', <https://www.artgallery.sa.gov.au/ agsa/home/About/Image_Requests/filming_requests.html>.

160. <http://www.artgallery.wa.gov.au/collections/copyright.asp >.

161. 'Visitors are permitted to take photographs with hand-held cameras in non-restricted areas within the National Gallery of Victoria for personal use. All restricted areas display signage at the entrance of the exhibition or gallery space advising of the photography restrictions. These images should not be reproduced or displayed on personal websites. The use of tripods, selfie sticks, flash or additional lighting is not permitted without the permission of the NGV. A request must be made and granted before such equipment can be used in any gallery spaces', <https:// www.ngv.vic.gov.au/about/reports-and-documents/19357-2/>.

162. As argued above, in most cases, copyright will not subsist in a slavish photographic copy of a two-dimensional work.

163. Whether the galleries' terms governing the taking of photographs are binding contractual terms between the gallery and the visitor is a question beyond the scope of this article, but an important one nevertheless.

164. Roadshow Films v iiNet Limited [2012] HCA 16. 


\section{CONCLUSION}

We have no Australian case affirming the logic of Bridgeman under Australian copyright doctrine. However, it is extremely likely that photographs of two-dimensional works that exhibit no creative choices by the photographer, and merely attempt to faithfully reproduce the expressive character of the photographed two-dimensional work, are not original. This applies to all photographs of two-dimensional objects, whether those objects are copyright works, orphan works, or in the public domain. The practical difference is that the reproduction of the photograph of a copyright work would indirectly infringe the photographed work, irrespective of the copyright status of the photograph. Thus misguided claims of copyright in photographs of copyright works are less offensive than claims of copyright in photographs of public domain works. This is because the latter claims have the effect of privatizing elements of the public domain through the medium of the photograph.

Photographs of three-dimensional objects pose more complex issues. Originality in such photographs is more tenuous and uncertain, however the very low originality threshold would suggest that the minimal decisions made by photographers about angle, framing and point of view would exhibit sufficient intellectual effort.

Cultural institutions are in an invidious position. Galleries are not copyright law experts, and copyright law, particularly originality, is often uncertain and slippery. It is a difficult task ascertaining the copyright status of myriad different works, many of which may be orphaned. There is risk in digitizing and releasing copyright content. ${ }^{165}$ Some works raise particular sensitivities and complexities, particularly indigenous expression, private confidential communications, and unpublished works. Galleries may be concerned about fostering copyright infringement by visitors. They may also legitimately seek to ensure the items in their collections are properly attributed and reproduced, and no doubt they are intent on preserving and generating every possible source of revenue that they can, particularly with diminishing government funding. They may question the logic of gratuitously releasing digital images to the global public when only the gallery's local tax payers have supported it. They may resent private commercial interests profiting from their images when they consistently struggle to fund their activities. Perhaps to circumvent these uncertainties and reconcile these tensions, galleries tend to impose blanket prohibitions on copying which have the effect of over-claiming.

Unfortunately, cultural institutions also have a positive obligation to enhance access to their collections. This entails digitizing their collections, because unavoidably, in this digital age, providing digital access is increasingly becoming a necessity rather than a discretionary indulgence. But creating digital records of their collections is only one step in improving access to those collections. Cultural institutions must also avoid setting up artificial and unsound barriers which obstruct access to those digital repositories. Those obstacles may be caused by a combination of interrelated factors which create and validate perceptions of authority over cultural objects and their digital surrogates. These are produced and perpetuated by flawed assertions of copyright in photographs of two-dimensional objects, which apparently legitimize entrenched licensing norms and contractual terms restricting uses of cultural objects and photographs of them. These very practices suggest an illusory authority to assert blanket rights over the use

165. E Hudson and A Kenyon, 'Digital Access: The Impact of Copyright on Digitisation Practices in Australian Museums, Galleries, Libraries and Archives' (2007) 30(1) UNSW Law Journal 12. 
of digital surrogates, which is underscored by the practical control over both the digital photographic files and the material objects conferred by galleries' possessory property rights.

It is incumbent on cultural institutions to more carefully refrain from unselectively claiming or implying copyright in all of the photographs of their collections, and recognize that only sufficiently original photographs confer a right to restrain dealings under copyright law. While galleries retain property rights in the digital photographic files, they should release the public domain images, consistent with their mandates to enhance access to cultural capital. ${ }^{166}$ Their funding woes should not be ameliorated by contracting the public domain, but addressed by the State.

It is the disseminative capacity of the photograph that makes it such an integral component in cultural sharing and explains its socio-cultural value. It is essential that images of public domain material be emancipated. Artistic surrogates have long played an essential role in cultural engagement. Today's digital surrogates are the contemporary version of the 'good, cheap copies' made by both pirates and legitimate sources in Australia's colonial past, permitting the embryonic Australian colonies to access European masters. ${ }^{167}$ Limiting access to digital proxies of public domain art through copyright or copyright-like claims not only contorts copyright, but ultimately risks diminishing the human right 'freely to participate in the cultural life of the community, to enjoy the arts and to share in scientific advancement and its benefits'. ${ }^{168}$

166. Note that the Australian Law Reform Commission's Terms of Reference for the Copyright and the Digital Economy inquiry expressly acknowledged 'the general interest of Australians to access, use and interact with content in the advancement of ... culture', Australian Law Reform Commission, Copyright and the Digital Economy Report No. 122 (2014) para 3.52.

167. K Bowrey, “"The World Daguerreotyped - What a Spectacle!" Copyright Law, Photography and the Commodification Project of Empire' (May 1, 2012), UNSW Law Research Paper No. 2012-18, available at SSRN: <https://ssrn.com/abstract=2060803>, 26-8. 168. Article 27(1) Universal Declaration of Human Rights (adopted 10 December 1948) UNGA Res 217 A(III) (UDHR) art 27. 